\title{
EFFECTS OF HOFMEISTER ANIONS ON DPPC LANGMUIR MONOLAYERS AT THE AIR-WATER INTERFACE
}

\author{
A. Aroti ${ }^{1}$, E. Leontidis ${ }^{1, *}$, E. Maltseva ${ }^{2}$ and G. Brezesinski ${ }^{2}$ \\ 1: Department of Chemistry, University of Cyprus, Nicosia 1678, Cyprus \\ 2: Max Planck Institute of Colloids and Interfaces, Potsdam 14424, Germany
}

\begin{abstract}
$\underline{\text { Abstract }}$
In this work we investigated the effect of sodium salts of different monovalent anions belonging to the Hofmeister series on Langmuir monolayers of DPPC (1,2-dipalmitoyl phosphatidylcholine). The salts used were $\mathrm{NaCl}, \mathrm{NaBr}, \mathrm{NaNO}_{3}, \mathrm{NaI}, \mathrm{NaBF}_{4}, \mathrm{NaClO}_{4}$ and NaSCN. The monolayer phase behavior and the morphology and structure of the lipid phases were studied by surface pressure - area isotherms, Brewster Angle Microscopy (BAM), Grazing Incidence X-ray Diffraction (GIXD) and Infrared Reflection-Absorption Spectroscopy (IRRAS). The presence of electrolytes in the subphase was found to increase the surface pressure at a fixed area per molecule, indicating a stabilization of the liquidexpanded phase of the monolayer. This increase is different for different anions and different electrolyte concentrations. X-Ray diffraction and infrared spectroscopy experiments show that moderate concentrations of chaotropic anions, such as $\mathrm{I}^{-}$, do not significantly change the conformation and packing properties of the hydrocarbon chains. The lattice parameters and the ordering of the lipid molecules in the liquid-condensed phase remain essentially unaffected even at quite high electrolyte concentrations. This finding suggests that anions partition into or bind to the looser liquid-expanded phase, thus providing entropic stabilization of that phase, but do not penetrate into or bind to the domains of the liquid-condensed phase. This intriguing result is discussed in terms of the possible modes of interaction of anions with lipid interfaces.
\end{abstract}




\section{Introduction}

The Hofmeister series of ions was initially established more than a century ago, when it was found that (a) the $\log$ (solubility) of many proteins in electrolyte solutions depends linearly on electrolyte concentration, and that (b) a different $\log$ (solubility) vs. salt concentration curve is obtained for each electrolyte. Anions were found to have a much stronger impact on protein solubility than cations. The anionic Hofmeister series orders anions with decreasing saltingout potency from left to right, and is as follows:

$$
\mathrm{SO}_{4}{ }^{2-}, \mathrm{HPO}_{4}{ }^{2-}, \mathrm{OH}^{-}, \mathrm{F}^{-}, \mathrm{HCOO}^{-}, \mathrm{CH}_{3} \mathrm{COO}^{-}, \mathrm{Cl}^{-}, \mathrm{Br}^{-}, \mathrm{NO}_{3}^{-}, \mathrm{I}^{-}, \mathrm{SCN}^{-}, \mathrm{ClO}_{4}^{-}
$$

It must be noted however that occasionally the order of anions in the series can be slightly different, depending on the phenomenon under examination. Numerous experiments over several decades have shown that the Hofmeister series plays significant roles in a dramatic range of biological and physicochemical phenomena, affecting the solubility of hydrophobic solutes in water, the cloud points of polymer and surfactant solutions, the action of ions on ion-channels, the activities of various enzymes, and the surface tension of electrolyte solutions to name just a few examples. ${ }^{1,2}$ After one century of research, the precise origin of action of the Hofmeister ions has not been clarified. ${ }^{1-3}$ Current ideas about the nature of specific salt effects vary: Many biologists still believe that ions act by modifying the structure of water close to biological interfaces. ${ }^{4}$ Others believe that the specific effects consist mainly of salting-in or salting-out of specific surface groups, ${ }^{3,5}$ and that these interactions are watermediated. ${ }^{6}$ Using such arguments it would be hard to explain the well known specific ion effect on the surface tension of electrolyte solutions. ${ }^{3,7,8}$ A recent proposition attempts to explain ion specificity by invoking dispersion interactions of ions with surfaces. ${ }^{8}$ An alternative qualitative model argues that ion specificity arises as a result of the fine balance between ion-water and water-water interactions. ${ }^{9}$ A similar point is made by recent computer simulation studies using Monte Carlo and Molecular Dynamics, which emphasize hydration 
interactions and examine specific effects of ions on the hydrogen bond network of water. ${ }^{10,11}$ It is safe to say that to date no consensus exists for the mechanism of specific ion effects, and it remains largely unclear whether ions act through precisely defined, specific, local interactions, or through more delocalized collective interactions. Elucidation of the mechanism of action of the Hofmeister ions in a particular experimental situation will provide valuable insights for a multitude of ion-specific phenomena, and will have a strong impact on biology and chemistry. In particular, the following important questions that remain unanswered today must be addressed:

(a) Is there a concentration threshold for specific ion effects to appear? (b) Are specific ion effects really interfacial phenomena? (c) Are specific ion effects based on local or on collective interactions? (d) Does a unique ion parameter exist to correlate ion effects?

In order to better understand the mechanism of action of Hofmeister anions, we need to work with model interfaces. The model systems used in this work are Langmuir monolayers of the lipid DPPC at the air-water interface in the presence of subphase electrolytes. The simplicity of the planar monolayer geometry offers a clear theoretical advantage for the evaluation and comparison of interfacial models of ion binding. In addition, the coexistence of various twodimensional phases on the water surface provides a unique opportunity to study ion-lipid interactions as a function of lipid chain packing and ordering under very well-defined conditions dictated by the surface pressure. ${ }^{12-15}$ Apart from being one of the major components of the cell membrane, DPPC was chosen because it is zwitterionic hence its interactions with anions will not be completely dominated by strong Coulomb interactions. Langmuir monolayers of DPPC have been studied with a vast array of methods over the past few decades and are very well characterized. The development of many new experimental techniques that provide details on the structure, ordering and morphology at the mesoscopic and the molecular level, such as grazing X-ray scattering, ${ }^{15,16}$ fluorescence microscopy ${ }^{17-19}$ 
and Brewster angle microscopy, ${ }^{20-22}$ renders DPPC monolayers especially attractive for our purposes.

The goal of this investigation is to obtain structural information showing the precise effects of the anions on the lipid interfacial structures, and eventually obtain meaningful and reproducible "binding constants" of anions on lipid monolayers. These binding constants can be subsequently correlated to analogous binding constants on other interfaces or to potential local interactions (hydration, dispersion, electrostatics etc.) to identify interaction mechanisms. Several investigations of the effects of cations on lipid bilayers ${ }^{23-28}$ and monolayers ${ }^{29-31}$ exist in the literature, given the importance of $\mathrm{H}^{+}, \mathrm{Na}^{+}, \mathrm{K}^{+}, \mathrm{Ca}^{2+}$ and $\mathrm{Mg}^{2+}$ in modulating biomembrane behavior. Anion effects on lipid bilayers have also been examined in the past, although not as extensively as cation effects. ${ }^{32-37}$ The latter investigations indicate that the effects of anions on zwitterionic lipid bilayers are substantial and follow the Hofmeister series. There are very few reports in the literature examining the effects of anions on lipid monolayers, most concentrating on positively charged lipids, for which the Coulomb interactions are overwhelmingly important. ${ }^{38,39}$ In old work with very low electrolyte concentrations in the subphase it was concluded that "anions do not affect the surface pressure of lecithin monolayers in any significant way". ${ }^{29}$ The recent molecular simulations of zwitterionic phospholipid bilayers in contact with electrolyte solutions typically place the emphasis of the investigation on lipid-cation interactions, ${ }^{40-42}$ an important exception being the very recent work of Sachs and Woolf, ${ }^{43}$ who discuss anion penetration into zwitterionic lipid bilayers, and conclude that large anions can penetrate more deeply into the bilayers and be somehow stabilized in the hydrophobic environment.

Our study provides a fresh look into the interactions between anions and monolayers in several respects. We examine the effects of anions on zwitterionic lipid monolayers in a systematic way, using several sodium salts of anions that cover the chaotropic side of the 
Hofmeister series. Sodium salts were chosen because sodium is thought to be an indifferent cation in the lyotropic series. ${ }^{9}$ We use a range of ion concentrations in the subphase, and apply the modern methods of Brewster angle microscopy (BAM), Grazing Incidence X-ray Diffraction (GIXD) and Infrared Absorption-Reflection Spectroscopy (IRRAS) to obtain extensive structural information about the DPPC monolayers in the presence of high electrolyte concentrations in the subphase for the first time. Our strategy is to understand salt effects on DPPC monolayers by gradually reducing the length scale of the investigation. We start from the macroscopic thermodynamic information of the pressure-area isotherms, then we examine the mesoscopic $(\mu \mathrm{m})$ scale with BAM, and finally move to the microscopic $(\mathrm{nm})$ scale with GIXD and the bond $(\AA)$ scale with IRRAS.

\section{Materials}

The phospholipid DPPC (1,2-dipalmitoyl-sn-glycero-phosphocholine) was obtained from Avanti Polar Lipids, and used without further purification. Chloroform (p.a. grade, Merck, Germany) was used as a solvent to prepare $1 \mathrm{mM}$ solutions of DPPC. All sodium salts were purchased from Sigma-Aldrich with purity $>99 \%$, with the exception of the salts $\mathrm{NaBF}_{4}$ and NaSCN, the purity of which was $>98 \%$. All salts were baked in an oven at $300{ }^{\circ} \mathrm{C}$ for 2 hours prior to solution preparation. Salt solutions were prepared using ultrapure water (specific resistance of $18.2 \mathrm{M} \Omega \mathrm{cm}$ ) produced by a Millipore reverse osmosis unit.

\section{Methods}

\subsection{Pressure-area isotherms of Langmuir monolayers}

Isotherm measurements were carried out with a KSV 3000 Langmuir trough (KSV Instruments, Finland) equipped with a Wilhelmy plate for the determination of the surface pressure with accuracy $\pm 0.01 \mathrm{mN} \mathrm{m}^{-1}$. The trough surface area was $864 \mathrm{~cm}^{2}$ and the subphase 
volume was $0.95 \mathrm{~L}$. All experiments were performed at $(22 \pm 0.1){ }^{\circ} \mathrm{C}$. The temperature of the subphase was maintained constant with a Julabo recirculating thermostat. DPPC monolayers were obtained by spreading $90 \mu \mathrm{l}$ of a $1 \mathrm{mM}$ chloroform solution of DPPC. After $10 \mathrm{~min}$ of evaporation time for the spreading solvent, the surface pressure - area isotherms were registered while compressing the monolayers at a constant speed of $10 \mathrm{~mm} / \mathrm{min}$. Different solvent evaporation times (10-30 $\mathrm{min})$ and different compression speeds (2-10 $\mathrm{mm} / \mathrm{min})$ were used as well, and were found to have little effect on the isotherms. For all concentrations of every salt used, DPPC isotherms were measured at least three times or as many times as necessary to obtain an accurate average isotherm.

\subsection{Brewster Angle Microscopy (BAM)}

A Brewster-angle microscope (BAM2 from NanoFilm Technology, Göttingen, Germany) was used to study the morphology of the lipid monolayers. The lateral resolution of the BAM2 with a $20 \mathrm{~mW}$ Laser of wavelength equal to $514 \mathrm{~nm}$ is $2 \mu \mathrm{m}$. Because the Brewster-angle changes with the refractive index of the subphase, which is influenced significantly by electrolytes, special care was taken to identify the correct Brewster-angle especially for salt solutions with high concentration. The Brewster-angle was always $>53.5^{\circ}$.

\subsection{Grazing Incidence X-ray Diffraction (GIXD)}

Grazing incidence X-ray diffraction was performed using the liquid-surface diffractometer at the undulator beamline BW1 at HASYLAB, DESY, Hamburg (Germany). A monochromatic synchrotron beam enters the surface at an angle of incidence $\alpha_{i}=0.85 \alpha_{c}$, where $\alpha_{c} \approx 0.13^{\circ}$ is the critical angle for total reflection. A linear position-sensitive detector was used to monitor the diffracted intensity as a function of the vertical scattering angle $\alpha_{\mathrm{f}}$. According to the 
geometry of diffraction, the scattering vector $\mathbf{Q}$ can be written in terms of an in-plane component $\mathrm{Q}_{\mathrm{xy}}$ and an out-of plane component $\mathrm{Q}_{\mathrm{z}},{ }^{15,16}$ where

$$
\mathrm{Q}_{\mathrm{xy}}=\frac{2 \pi}{\lambda} \sqrt{\cos ^{2} \alpha_{\mathrm{i}}+\cos ^{2} \alpha_{\mathrm{f}}-2 \cos \alpha_{\mathrm{i}} \cos \alpha_{\mathrm{f}} \cos 2 \theta}
$$

and

$$
\mathrm{Q}_{\mathrm{z}}=\frac{2 \pi}{\lambda}\left(\sin \alpha_{\mathrm{i}}+\sin \alpha_{\mathrm{f}}\right) \approx \frac{2 \pi}{\lambda} \sin \alpha_{\mathrm{f}} \quad \text { when } \alpha_{\mathrm{i}}<<\alpha_{\mathrm{f}}
$$

The in-plane component provides information about the lattice spacings

$$
\mathrm{d}_{\mathrm{hk}}=\frac{2 \pi}{\mathrm{Q}_{\mathrm{xy}}}
$$

while the out-of plane component can provide information about the polar tilt angle $t$ and the chain tilt direction $\Psi$ (azimuth $\Psi) .^{44,45}$

$$
\mathrm{Q}_{\mathrm{z}}^{\mathrm{hk}}=\mathrm{Q}_{\mathrm{xy}}^{\mathrm{hk}} \cos \Psi_{\mathrm{hk}} \mathrm{tant}
$$

\subsection{Infrared Reflection-Absorption Spectroscopy (IRRAS)}

IRRAS spectra were recorded using the IFS 66 FT-IR spectrometer (Bruker, Germany) equipped with a liquid nitrogen-cooled MCT detector. The IR beam was conducted out of the spectrometer and focused onto the water surface of the Langmuir trough. A detailed description of the instrumental setup has been given elsewhere. ${ }^{46}$ The angle of incidence of the IR beam, polarized by a $\mathrm{BaF}_{2}$ polarizer in the plane of incidence (p) and perpendicular to this plane (s), with respect to the surface normal was $40^{\circ}$ or $62^{\circ}$. The spectral resolution was 8 $\mathrm{cm}^{-1}$. Measurements were made by switching between two troughs at regular intervals using a trough shuttle system controlled by the acquisition computer. One trough contains the monolayer system under investigation (sample), whereas the other (reference) is filled with pure subphase. The spectra from the reference trough were subtracted from the sample spectra in order to eliminate the water vapor signal. To maintain a constant water vapor content the 
set-up was placed in a hermetically sealed container. Spectra were recorded with a spectral resolution of $8 \mathrm{~cm}^{-1}$ and collected using 200 - 400 scans. 


\section{4. $\underline{\text { Results }}$}

\subsection{Pressure-Area Isotherms}

Different sodium salt solutions with concentrations between 0.1 and $0.5 \mathrm{M}$ (and sometimes up to $1.5 \mathrm{M}$ ) were used as subphases for the monolayer study. Figure 1 illustrates the influence of different concentrations of NaI on DPPC monolayer isotherms.

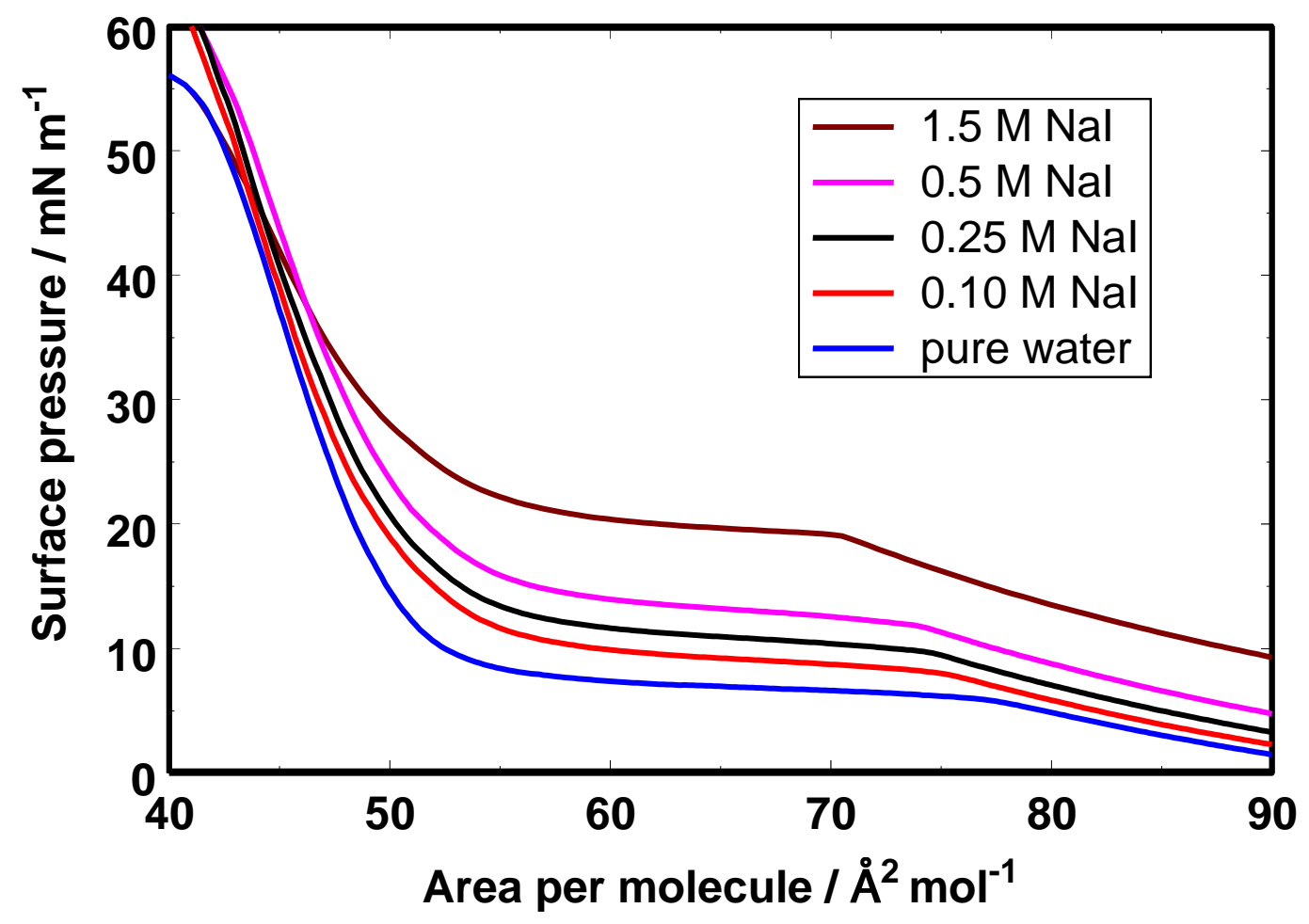

Figure 1: Surface pressure - molecular area isotherms of DPPC on NaI solutions of various concentrations at $22{ }^{\circ} \mathrm{C}$.

As a general observation, the presence of salt in the subphase increases the surface pressure at a fixed area per molecule, the effect being more pronounced at higher areas per molecule and less so at high surface pressures. DPPC monolayers exhibit a main phase transition producing a plateau region in the pressure - area isotherm. The transition from the liquid expanded (LE) to the liquid condensed (LC) phase is shifted to higher surface pressures and smaller 
molecular areas and the plateau becomes shorter as the salt concentration increases. The $\pi$-A isotherms of DPPC on pure water and on $0.1 \mathrm{M}$ solutions of various sodium salts are presented in Figure 2.

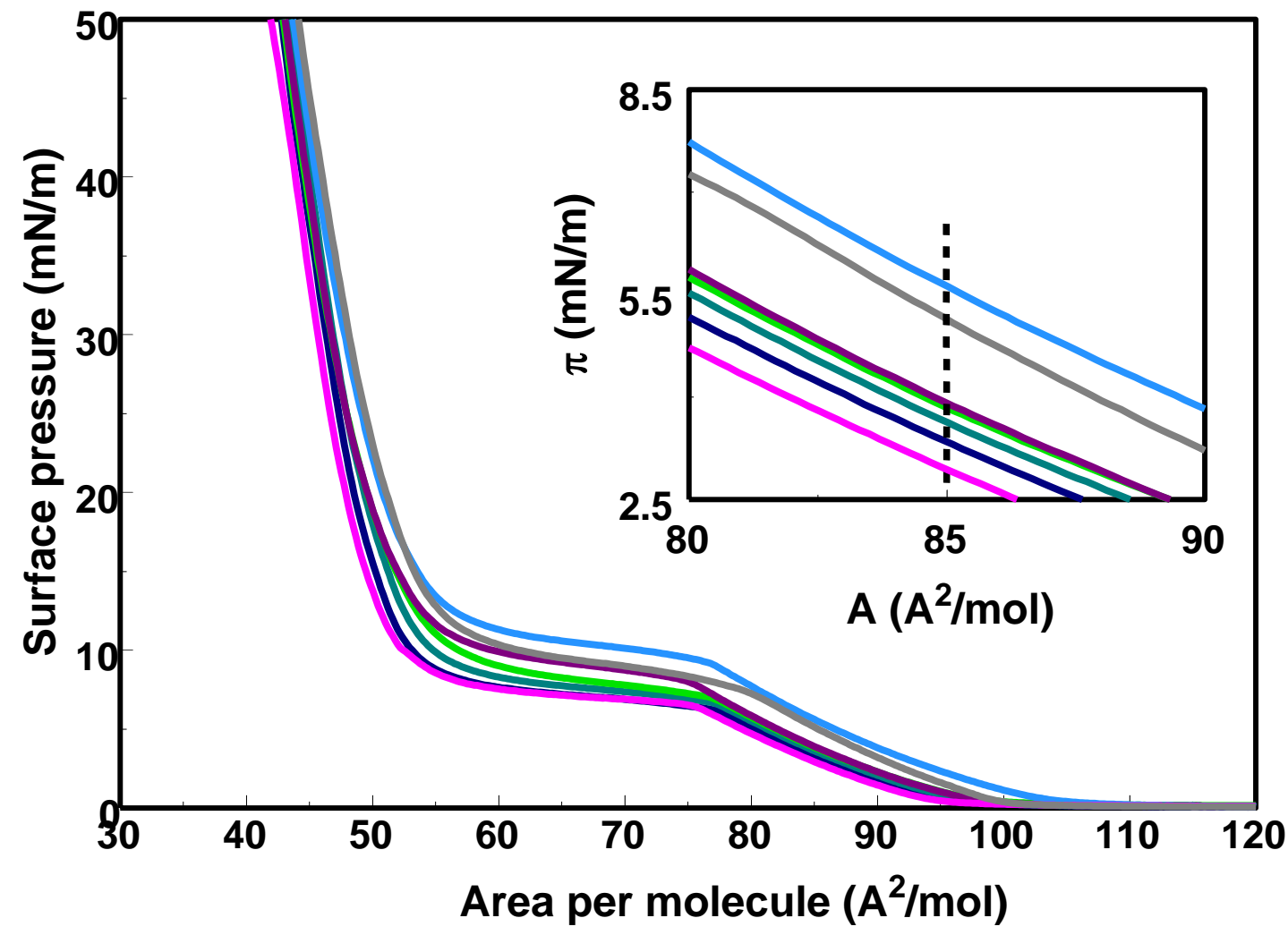

Figure 2: Surface pressure - molecular area isotherms of DPPC monolayers at $22{ }^{\circ} \mathrm{C}$ on different 0.1 $\mathrm{M}$ sodium salt solutions used as subphases. From bottom to top: DPPC on water, $\mathrm{NaCl}, \mathrm{NaBr}$, $\mathrm{NaNO}_{3}, \mathrm{NaI}, \mathrm{NaBF}_{4}, \mathrm{NaClO}_{4}, \mathrm{NaSCN}$

It can be seen that the increase in surface pressure is different for different anions and the magnitude of the increase follows the order: $\mathrm{Cl}^{-}<\mathrm{Br}^{-}<\mathrm{NO}_{3}{ }^{-}<\mathrm{I}^{-}<\mathrm{BF}_{4}{ }^{-}<\mathrm{ClO}_{4}{ }^{-}<\mathrm{SCN}^{-}$. The effect of anions follows the order of the Hofmeister series with $\mathrm{ClO}_{4}{ }^{-}$appearing in front of $\mathrm{SCN}^{-}$. As an illustration of the Hofmeister effect of salts on DPPC, we plot in Figure 3 the surface pressure as a function of the square root of salt concentration for a lipid area of $85 \AA^{2}$ per molecule. 


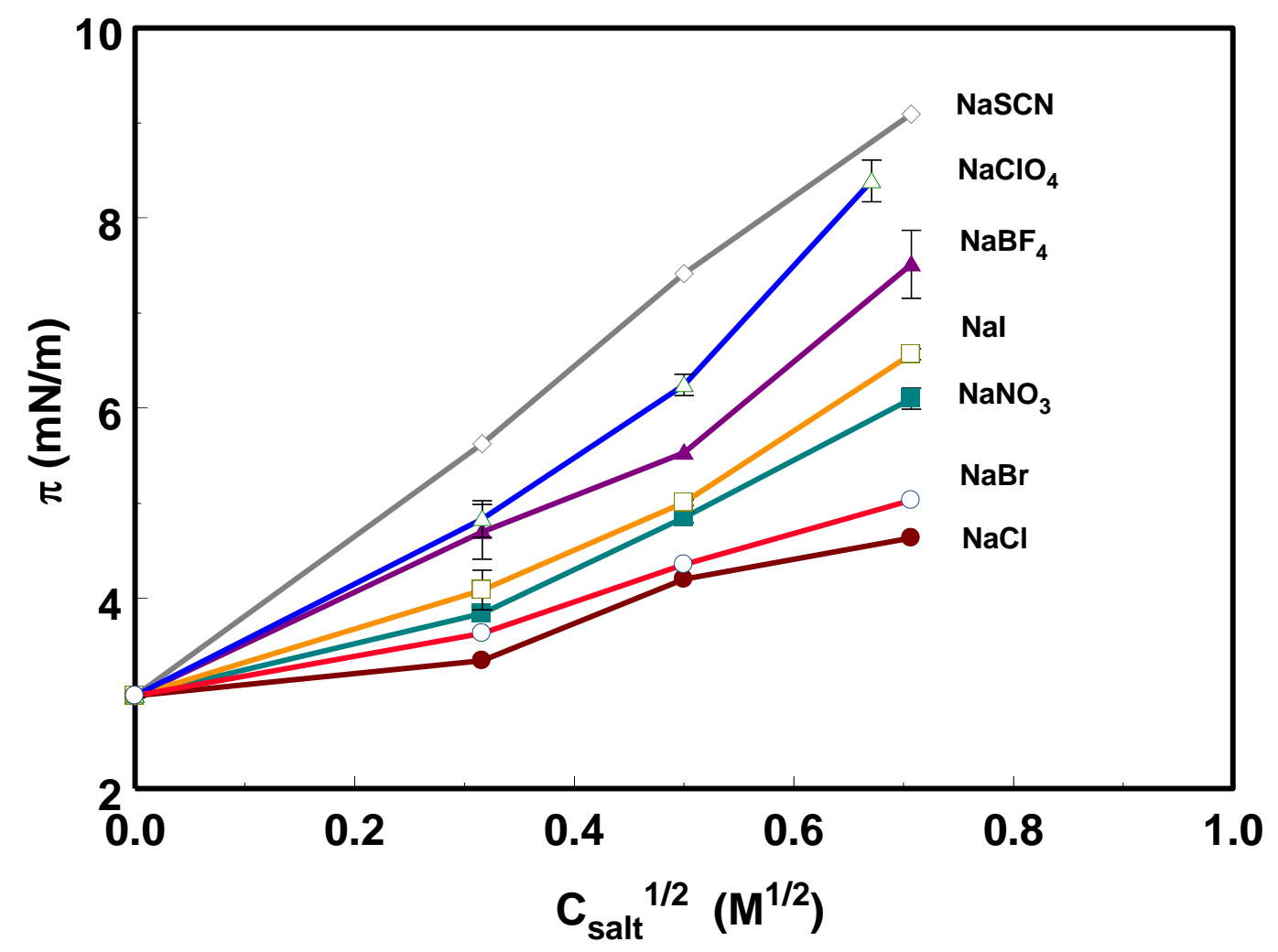

Figure 3: Monolayer surface pressure as a function of the square root of salt concentration in the subphase. The area per molecule is $85 \AA^{2}$, and the temperature is $22{ }^{\circ} \mathrm{C}$.

We obtain approximate straight lines, the slopes of which follow the Hofmeister series. In most cases we provide the error bars of the experimental points to make clear that we are observing a genuine effect that is beyond experimental uncertainty. The general conclusion from Figures 1 to 3 is that the effect of anions on the DPPC isotherms is substantial. It appears that the LE phase is stabilized in the presence of high concentrations of salts in the subphase. What happens to the LC phase is examined below with methods that can yield information at much shorter length scales.

\subsection{Domain Morphology -Brewster angle microscopy}


The Brewster angle microscope allows direct observation of the nucleation and growth and the final structure of the condensed-phase (LC) domains of lipid monolayers. ${ }^{20}$ The morphology (size and shape) of DPPC monolayer domains in particular has been thoroughly studied over the past 20 years with fluorescence ${ }^{17-20}$ and Brewster angle microscopy. ${ }^{21,22,47-49}$ We have obtained BAM images of DPPC monolayers on subphases containing sodium salts of various anions with concentrations ranging between 0.1 and $1.5 \mathrm{M}$. Figure 4 shows the shape and size of LC phase domains of DPPC for a surface area of ca. $(56 \pm 1) \AA^{2}$ per molecule on different $1 \mathrm{M}$ salt solutions.
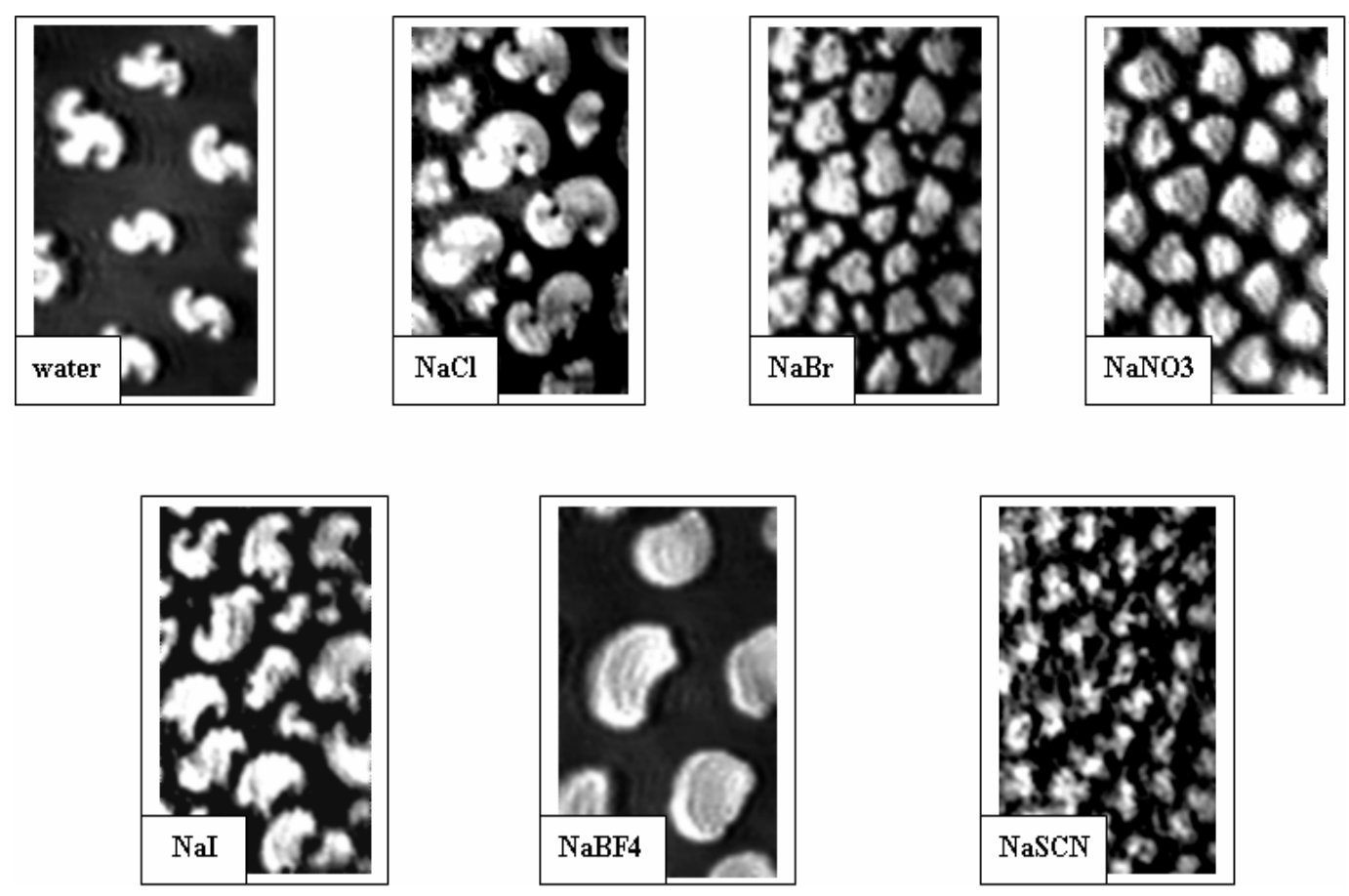

Figure 4: BAM images of LC phase domains of DPPC for a surface area of ca. $(56 \pm 1) \AA^{2}$ per molecule in the presence of $1 \mathrm{M}$ solutions of $\mathrm{NaCl}, \mathrm{NaBr}, \mathrm{NaNO}_{3}, \mathrm{NaI}, \mathrm{NaBF}_{4}$ and $\mathrm{NaSCN}$. A picture of a DPPC monolayers on pure water at $56 \AA^{2}$ per molecule is also included for comparison.

An image of a DPPC monolayer on a pure water subphase at the same area per lipid is also added for comparison. Although some differences between various electrolytes can be 
discerned, the overall impression from Figure 4 is that the shapes of the domains are not very sensitive to the specific salt in the subphase. One can see of course that $\mathrm{Cl}^{-}$does not affect significantly the domain morphology of DPPC monolayers, while $\mathrm{Br}^{-}, \mathrm{NO}_{3}{ }^{-}$and $\mathrm{I}^{-}$make the LC domains more rounded. $\mathrm{BF}_{4}^{-}$has a stronger effect on the size and shape of DPPC domains and $\mathrm{SCN}^{-}$(the most chaotropic ion) reduces the size of the LC domains drastically. For concentrations of salts lower than $0.5 \mathrm{M}$ the different anions mainly change the density of LC domains on the surface and not their size and shape (results not shown). Figure 5 presents BAM images of LC domains on $\mathrm{NaI}$ solutions of concentrations from $0.1 \mathrm{M}$ to $1.5 \mathrm{M}$.
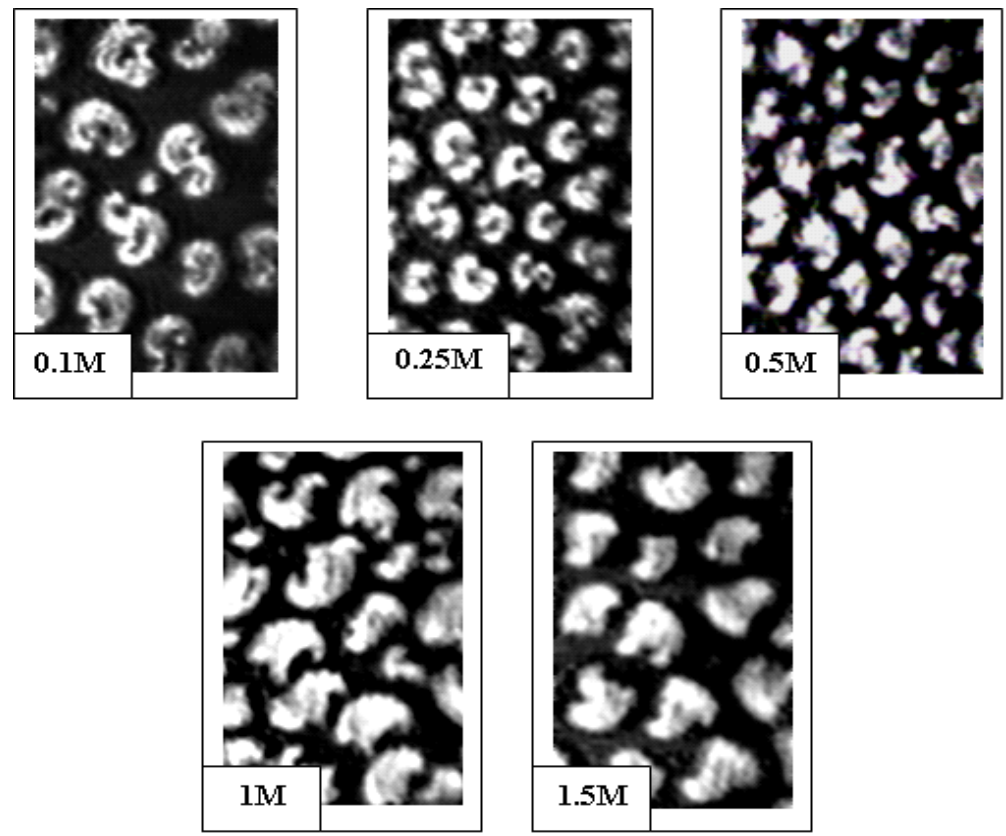

Figure 5: BAM images of LC domains of DPPC on NaI solutions of concentrations from $0.1 \mathrm{M}$ to $1.5 \mathrm{M}$.

The shape of the domains loses its characteristic "triskelion" geometry as the NaI concentration increases and becomes more rounded but still not isotropic. Since the observed differences are rather small however, we did not consider it necessary to analyze domain shapes to obtain their characteristic descriptors according to recently developed methods. ${ }^{50}$ 
Interpretation of BAM pictures is not easy, since they have been found to depend on the rate of compression of the monolayer, but the general consensus for lipid monolayer domains is that their shape is determined by the competition between line tension and electrostatic interactions, the former favoring rounded domains and the latter more elongated domains. ${ }^{19,48-}$ 52 There are two possible effects of anions: (a) Adsorption on the DPPC domains, which would then become charged. Electrostatics would then dominate and the domains should get more elongated. This is clearly not observed. (b) Gradual screening of the dipole potentials, leading to weakened electrostatic forces and rounding of the domain shape. This is closer to our observations. In addition, the results of the BAM investigation are in agreement with the observed fact that the electrolytes appear to stabilize the LE phase. In this case the line tension of the lipid-water system should decrease, giving rise to a higher domain density and to fuzzier domains, as is indeed observed in Figures 4 and 5.

\subsection{Grazing Incidence X-ray Diffraction}

GIXD was used to obtain information about the two-dimensional packing and the chain tilt of DPPC molecules at the air-water interface in the presence of $\mathrm{NaBr}$ or $\mathrm{NaI}$ in the subphase. Measurements were made at $22{ }^{\circ} \mathrm{C}$ at surface pressures of $15,25,35$, and $45 \mathrm{mN} \mathrm{m}^{-1}$ and for salt concentrations of 0.5 and $1.5{\mathrm{M} . \mathrm{Br}^{-}}^{-}$and $\mathrm{I}^{-}$were chosen as the anions because they were found to affect the pressure-area isotherms (Figure 3) to a different extent, $\mathrm{Br}^{-}$perturbing the monolayers less than $\mathrm{I}^{-}$, which is more chaotropic. In general, the measured scattering curves can be described by either two or three Bragg peaks. In the first case the in-plane lattice is orthorhombic, while in the second case the lattice is oblique. However, if we use three Bragg peaks, the two peaks at higher $\mathrm{Q}_{\mathrm{z}}$ are strongly overlapping and can be resolved only by a fitting procedure. Such a scattering pattern implies that the oblique lattice of tilted alkyl chains is very close to orthorhombic packing. ${ }^{15,16}$ The calculation of lattice parameters and 
chain tilt gives so similar data in the two cases that we decided to use a rectangular unit cell for simplicity. The calculated lattice parameters $a, b$ and $\gamma$ of the DPPC chain lattice and the tilt angles for DPPC monolayers on 0.5 and 1.5 M salt solutions are presented in Table 1, in which we also list the data for a DPPC monolayer spread on a pure water subphase for comparison. Table 1 reveals that the DPPC liquid-condensed phase is very little affected by the presence of high $\mathrm{Br}^{-}$concentration in the subphase. The cell parameters, the chain tiltangle and the unit cell distortion are very similar in the presence and the absence of $\mathrm{NaBr}$. This can also be seen in Figure 6, which shows the scattered intensity as a function of the inplane component $\mathrm{Q}_{\mathrm{xy}}$ and out-of-plane component $\mathrm{Q}_{z}$ of the scattering vector for DPPC monolayers at 25 and $45 \mathrm{mN} / \mathrm{m}$ on pure water, on $0.5 \mathrm{M} \mathrm{NaBr}$ solution and on $0.5 \mathrm{M} \mathrm{NaI}$ solution.

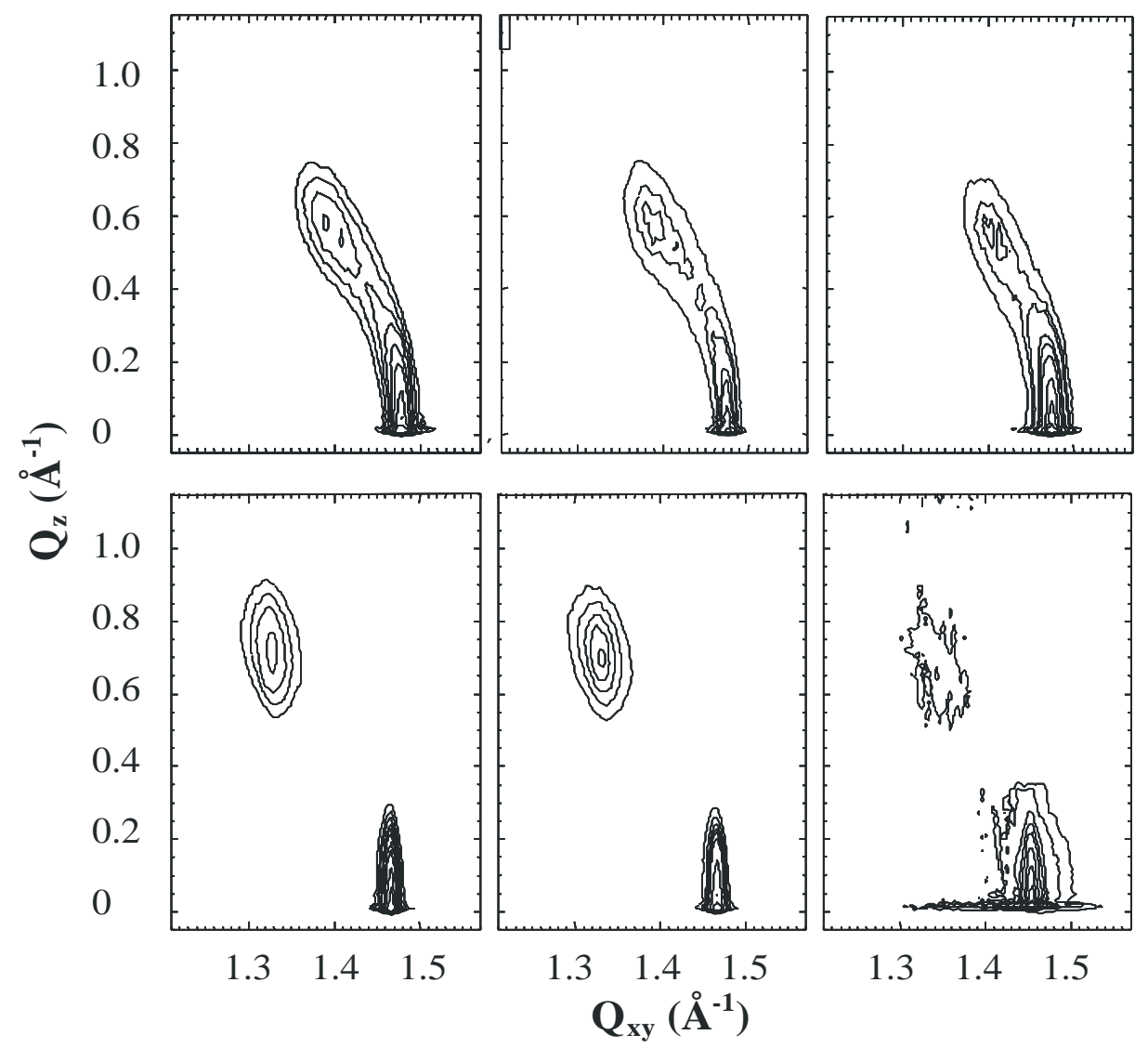

Figure 6: Contour plots of the corrected $X$-ray intensities as a function of in-plane $\mathrm{Q}_{\mathrm{xy}}$ and out-ofplane $\mathrm{Q}_{z}$ scattering vector components for a DPPC monolayer on water (left), on $0.5 \mathrm{M} \mathrm{NaBr}$ (middle) and on $0.5 \mathrm{M} \mathrm{NaI}$ (right) at $\pi=25 \mathrm{mN} / \mathrm{m}$ (bottom) and $45 \mathrm{mN} / \mathrm{m}$ (top). 
The GIXD results imply that $\mathrm{Br}^{-}$ions do not penetrate into or bind to the LC phase, because in that case we should observe significant changes of the unit cell parameters. Interestingly, in all cases the diffraction pattern with distinct peaks at low surface pressure changes to a pattern with the scattering intensity more distributed along an arc. The reason for such a change could be that at low pressure the molecules are able to pack in a lattice with defined tilt angle and tilt direction. Pressure increase leads obviously to packing problems, and such an intensity distribution can be described by assuming a fixed tilt angle but a variable tilt direction. Measurements on $\mathrm{NaI}$ solutions reveal some additional special features. On a $0.5 \mathrm{M} \mathrm{NaI}$ solution, there are no diffractions peaks at $15 \mathrm{mN} / \mathrm{m}$. At $25 \mathrm{mN} / \mathrm{m}$ the scattering intensity is still much less compared with the other experiments. Only the (02) Bragg peak close to the horizon can be clearly seen. Therefore, Table 1 shows only the data for $35 \mathrm{mN} / \mathrm{m}$ and 45 $\mathrm{mN} / \mathrm{m}$. These data show that the tilt angle of the chains is smaller compared with DPPC on water or on $\mathrm{NaBr}$. A smaller tilt angle could be an indication for a changed head group conformation or hydration. The head group needs now less space and the tilt of the chains is therefore reduced. This could be the result of interactions of the head group with the $\mathrm{I}^{-}$ions. However, there could be also another explanation, which is supported by the results obtained at higher salt concentrations. Much less scattering is observed using $1.5 \mathrm{M} \mathrm{NaI}$ even at the highest surface pressure examined $(45 \mathrm{mN} / \mathrm{m})$. Additionally, only one broad peak close to zero $\mathrm{Q}_{\mathrm{z}}$ can be seen (Figure 7). 

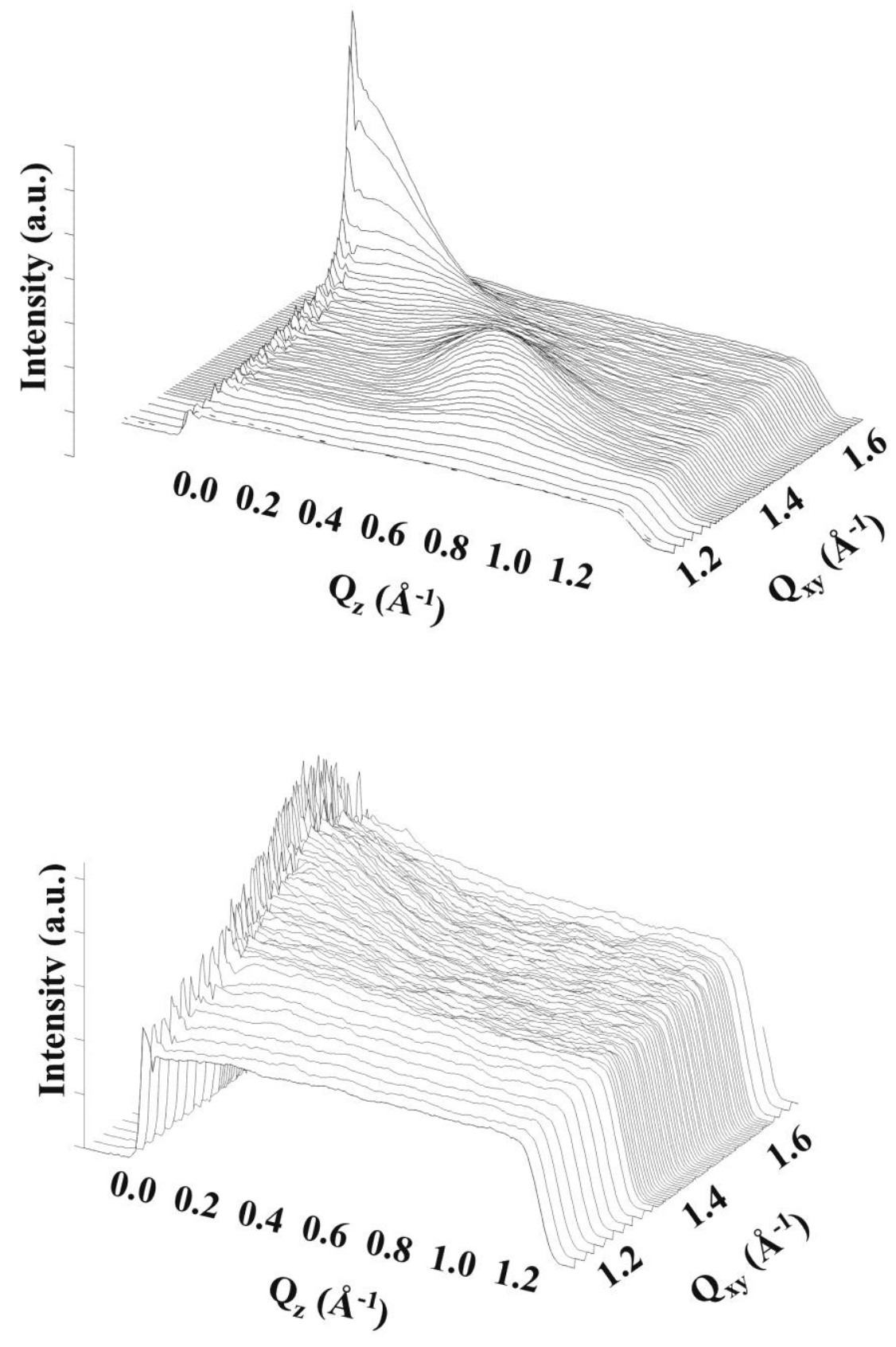

Figure 7: 3D-plots of the corrected X-ray intensities as a function of in-plane $\mathrm{Q}_{\mathrm{xy}}$ and out-of-plane $\mathrm{Q}_{z}$ scattering vector components for a DPPC monolayer on water (top) and on $1.5 \mathrm{M} \mathrm{NaI}$ (bottom) at $\pi=$ $35 \mathrm{mN} / \mathrm{m}$ and $\mathrm{T}=22{ }^{\circ} \mathrm{C}$. 
This shows that the LC phase is strongly disturbed. One reasonable explanation, especially considering the isotherm results and the IRRAS experiments, is that radicals produced by the high energy X-ray beam lead to an oxidation reaction producing iodine. Iodine itself can penetrate into the hydrophobic region of the DPPC monolayer and disturbs the packing properties to a large extent.

\subsection{Infrared Reflection-Absorption Spectroscopy}

Infrared Reflection-Absorption Spectroscopy (IRRAS) was used to provide additional information about the influence of high concentrations of the chaotropic anion $\mathrm{I}^{-}$on DPPC monolayers. The IR spectra of a DPPC monolayer on a $1.5 \mathrm{M} \mathrm{NaI}$ solution were recorded at $20{ }^{\circ} \mathrm{C}$ for different surface pressures. Previous FT-IR studies have shown that changes in the wavenumbers and intensities of specific bands provide valuable information on chain conformation $\left(v_{a s} \mathrm{CH}_{2}, v_{s} \mathrm{CH}_{2}\right), \mathrm{H}$-bonding, hydration and ion binding on the headgroup of the lipid $\left(v \mathrm{CO}, v_{a s} \mathrm{PO}_{2}{ }^{-}\right){ }^{53}$ Particularly interesting are the $\mathrm{C}-\mathrm{H}$ stretching bands of the saturated hydrocarbon chains between 3000 and $2800 \mathrm{~cm}^{-1}$, and the region between 1250 and $1000 \mathrm{~cm}^{-}$ 1, which gives information about the vibrations of the phosphate headgroup. Characteristic frequencies for DPPC on pure water and on a $1.5 \mathrm{M} \mathrm{NaI}$ solution at selected surface pressures are given in Table 2. The two bands at ca. $2851 \mathrm{~cm}^{-1}$ and ca. $2920 \mathrm{~cm}^{-1}$ are due to the symmetric and antisymmetric $\mathrm{CH}_{2}$ stretching vibrations of the alkyl chains of the phospholipids, respectively. It has been observed that during the main phase transition in DPPC monolayers the symmetric $\mathrm{CH}_{2}$ stretching frequency decreases from 2855 to $2851 \mathrm{~cm}^{-1}$ and the asymmetric $\mathrm{CH}_{2}$ decreases from 2924 to $2919 \mathrm{~cm}^{-1}$ indicating an increase of trans over gauche conformations and a higher degree of order. ${ }^{54}$ The frequencies observed (Table 2) show that up to $25 \mathrm{mN} / \mathrm{m}$ the order of the hydrocarbon chains is decreased in presence of $\mathrm{I}^{-}$ with respect to that of DPPC molecules on pure water indicating a higher content of gauche 
conformations. This is a further proof that $\mathrm{I}^{-}$ions in the subphase enhance the stability of the disordered LE phase of DPPC monolayers. At higher lateral pressures, the same stretching frequencies (hence the same conformation of the alkyl chains) as on pure water (all-trans conformation) are observed. This observation suggests that $\mathrm{I}^{-}$anions do not affect the LC phase, which is recovered unchanged at high pressures. However the LE/LC phase transition pressure in the DPPC monolayer increases with increasing concentration of $\mathrm{I}^{-}$ions.

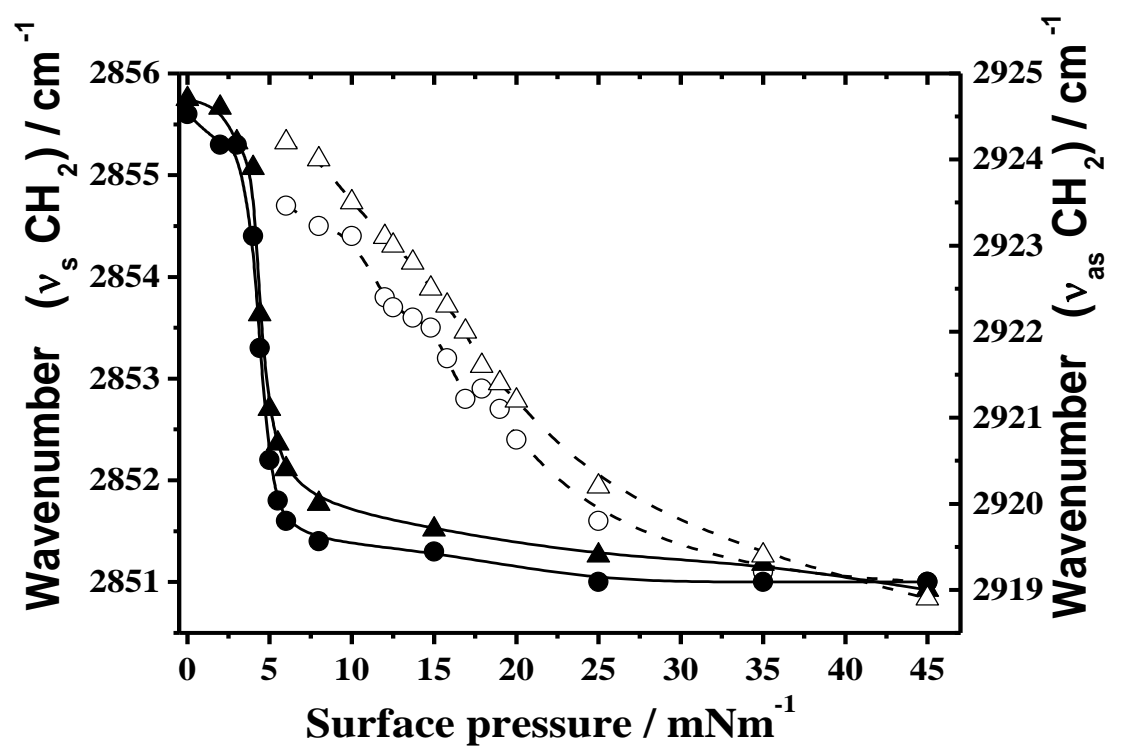

Figure 8: $\mathrm{CH}_{2}$ symmetrical (left axis, circles) and asymmetrical (right axis, triangles) stretching vibrations of DPPC monolayer on pure water (solid symbols) and on a $1.5 \mathrm{M} \mathrm{NaI}$ aqueous solution (open symbols) as a function of lateral surface pressure. The lines are drawn to guide the eye. spolarized light under an angle of incidence of $40^{\circ}$ normal to the surface was used.

Additionally, at high salt concentration the transition observed with IRRAS (Figure 8) is smeared over a larger pressure range. A final observation is that the asymmetric $v_{a s} \mathrm{PO}_{2}{ }^{-}$ stretching frequency at ca. $1230 \mathrm{~cm}^{-1}$ decreases slightly in the presence of $\mathrm{I}^{-}$indicating an increase in the average hydration of the phosphate group.

\section{Discussion and conclusions}


As shown in Figures 1 to 3, the addition of electrolytes in the subphase of DPPC monolayers leads to a general increase of the surface pressure at a fixed molecular area and the main transition pressure $\pi_{\mathrm{t}}$, which depends on the salt concentration and the type of anion in the subphase. The general increase of the surface pressure for all electrolytes implies that the salts adsorb at the DPPC monolayer in some way. There is an interesting contrast between the present results and the quantitative results of anion adsorption at oil/water microemulsion interfaces. $^{58}$ The initial slopes of the approximate straight lines of Figure 3 are useful "Hofmeister" parameters and can be plotted against other such parameters. We have plotted these slopes as a function of the Henry's law constants for anion adsorption to microemulsion interfaces, reported in Ref. 58. This plot is available as Supplementary material of this article. Although there were only four common anions in the two investigations, the correlation is excellent. The Henry constants can be negative (some anions are repelled from the microemulsion interfaces), while all $\mathrm{d} \pi / \mathrm{dC}-\mathrm{C}^{1 / 2}$ slopes in Figure 3 are positive. The excellent correlation implies a similar type of ion-interface interaction in the two cases.

The liquid-expanded phase appears to be favored in the presence of electrolytes. Surprisingly, the shape of the LC phase domains is not strongly influenced by the electrolytes. The fact that in the presence of electrolytes the domains become rounder instead of more elongated implies that the electrostatic term, which determines their shape, decreases in the presence of salt. This can be understood as a screening effect, and it suggests that anions do not bind to the LC domains. The GIXD results provide definite evidence that the structure of the LC phase is largely insensitive to the type and concentration of anions in the subphase. The different results for high concentrations of $\mathrm{NaI}$ are not the result of electrostatic interactions between $\mathrm{I}^{-}$ and the PC head group but can be understood by the formation of iodine due to a radicalmediated oxidation reaction, which destroys the chain packing. The IRRAS measurements show that on a highly concentrated $\mathrm{NaI}$ subphase the proportion of gauche conformers in the 
alkyl chains is much enhanced at low pressure and that the LE/LC phase transition is extended over a wider range of surface pressures.

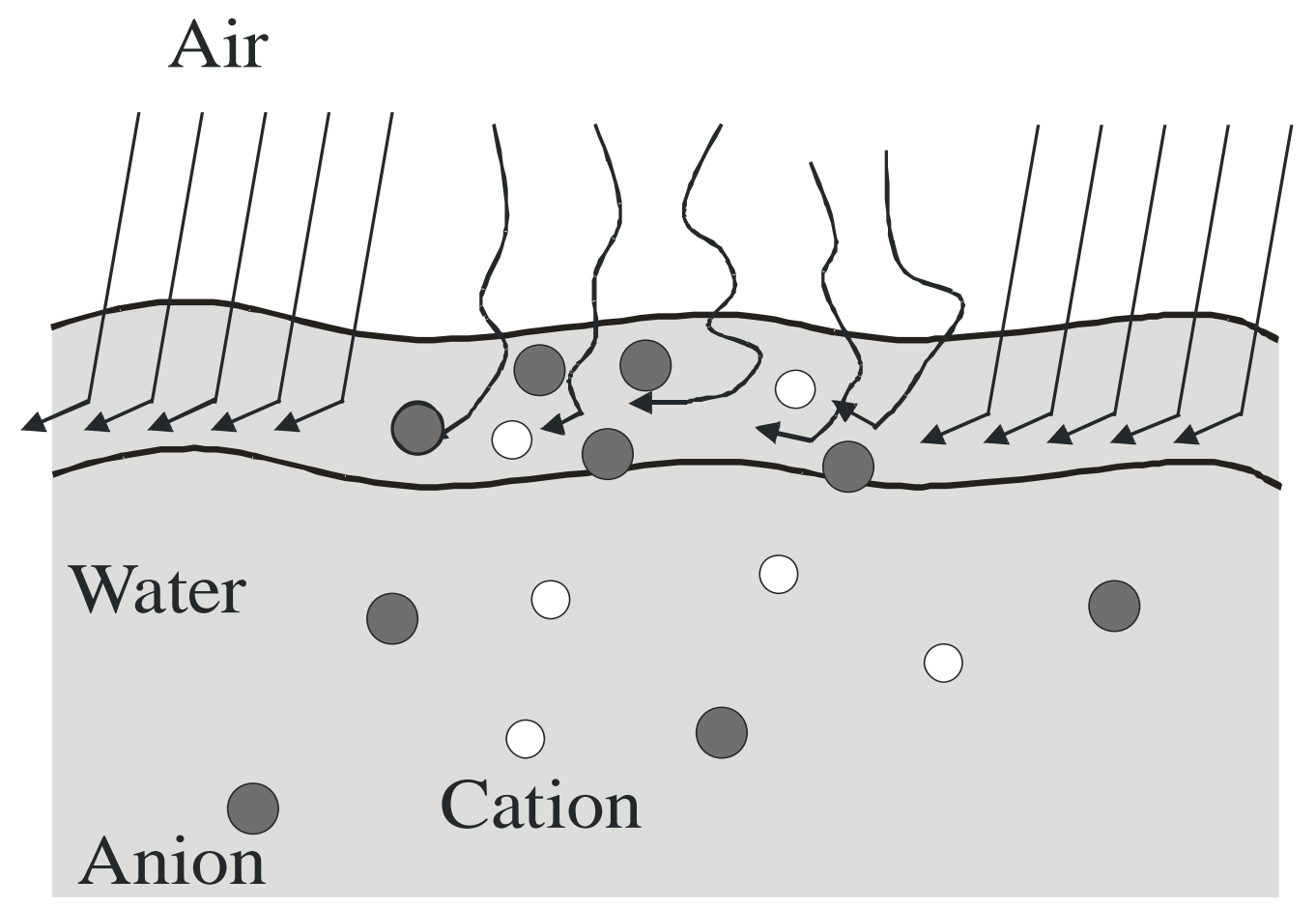

Figure 9: Schematic representation of the behavior of ions in a DPPC monolayer in the presence of both LC and LE phases. Ions do not penetrate into or bind to the LC phase, but partition in the LE phase.

The emerging picture is summarized in Figure 9. Here we see that ions penetrate into the disordered LE phase more easily, either binding to the lipids or partitioning in the phase in a more delocalized way. On the contrary, the ions do not interact strongly with the LC phase. The trend of increased surface pressures for the more chaotropic anions can be understood by evoking two different, not necessarily conflicting pictures:

(a) There is preferential adsorption of anions compared to sodium in the head group region, which is greater for the more chaotropic anions. This adsorption may occur either through strong local binding $^{6}$ or through dispersion forces. ${ }^{8}$ As a result the monolayer 
acquires an excess of negative charge, and there is an expansion of the LE phase at fixed pressure or equivalently an increased pressure at fixed area.

(b) There is no preferential binding, but the anions are expelled from the subphase and enter the disordered LE phase, because there is a free energy gain for water in this way leading to a net gain in free energy for the whole system. ${ }^{9}$ This monolayer penetration is stronger for the more chaotropic ions. This may or may not result in the creation of excess negative charge, depending on the amount of cations that enter the LE phase as well. The crucial result in this picture is an increase of the entropy of the LE phase, which is thus entropically stabilized.

It is important to understand which of the two mechanisms is really acting, because this will strengthen our understanding of the Hofmeister effect considerably. We are currently working on this issue by measuring the monolayer surface potential in the presence of ions and by analyzing the pressure-area isotherms at low surface pressures, at which only the LE phase exists, with a variety of binding and partitioning models. Two pieces of evidence from the previous investigation appear to favor the above described mechanism (b): First, if anions are strongly and specifically bound to the lipids this should happen for the LC phase as well, which would presumably give completely different BAM images and GIXD results. The counter argument is that the LC phase is very ordered and that the positive choline groups are not available for ion binding, being ion-paired to neighboring phosphate groups in the crystal lattice. A second argument is based on the fact that many pressure-area isotherms appear to converge at high surface pressures and that infrared frequencies approach those of DPPC on pure water at high pressures. This implies that ions are "squeezed out" from the monolayer at high pressures, and it is not obvious how this would be possible if strong local binding were happening. Such "squeezing-out" of ions from monolayers was recently observed by Motschmann, ${ }^{39}$ and bears a rough connection to the squeezing-out observed for larger 
hydrophobic molecules as the monolayers surface pressure increases. ${ }^{55-57} \mathrm{~A}$ strong nonspecific penetration of anions into lipid phases has been found in the recent Molecular Dynamics simulations of Sachs and Woolf. ${ }^{43}$

We leave the question open for the time being, as we summarize what has been accomplished in this investigation. For the first time we have carried out a detailed fundamental investigation of the effect of anions on DPPC monolayers at the air-water surface. The effect of the anions was found to be significant and we have tried to understand it by application of an array of methods that provided information at all length scales. The central result found so far is that anions interact strongly with the LE phase, but perturb the LC phase at best very weakly. This conclusion can be stated in the following alternative way: Specific ion effects will be least noticeable on well-organized, "flawless" or rigid interfaces, where the entropy gain from their presence is minimal.

\section{Acknowledgment}

Financial support for this work was provided by the French-German Network, Commissariat de l' Energie Atomique (CEA) Saclay, France and by the Max Planck Institute of Colloids and Interfaces Golm/Potsdam, Germany. We thank HASYLAB (DESY, Hamburg, Germany) for providing beamtime. 


\section{References}

(1) Collins, K. D.; Washabaugh, M. W. Quart. Rev. Biophys. 1985, 18, 323.

(2) Cacace, M. G. ; Landau, E. M. ; Ramsden, J. J. Quart. Rev. Biophys. 1997, 30, 241.

(3) Baldwin R. L. Biophys. J. 1996, 71, 2056.

(4) Chaplin M. F. Biophys. Chem. 1999, 83, 211.

(5) Clarke, R. J.; Lüpfert, C. Biophys. J. 1999, 76, 2614.

(6) Lyklema, J. Adv. Colloid Int. Sci. 2003, 100-102, 1.

(7) (a) Jarvis, N. L.; Scheiman, M. A. J. Phys. Chem. 1968, 72, 74. (b) Weissenborn, P. K.; Pugh, R. J. J. Colloid Int. Sci. 1996, 184, 550.

(8) (a) Ninham, B.W., Yaminsky, V., Langmuir 1997, 13, 2097-2108. (b) Boström, M.; Williams, D. R. M.; Ninham, B. W. Phys. Rev. Let. 2001, 87, 168103. (c) Boström, M.; Williams, D. R. M.; Ninham, B. W. Langmuir 2001, 17, 4475. (d) Boström, M.; Williams, D. R. M.; Ninham, B. W. Langmuir 2002, 18, 6010. (e) Boström, M.; Williams, D. R. M.; Stewart, P. R.; Ninham, B. W. Phys. Rev. E 2003, 68, 041902.

(9) (a) Collins, K. D. Proc. Natl. Acad. Sci. USA 1995, 92, 5553. (b) Collins, K. D. Biophys. J. 1997, 72, 65 .

(10) Karlström, G.; Hagberg, D. J. Phys. Chem. B 2002, 106, 11585.

(11) Hribar, B.; Southall, N. T.; Vlachy, V.; Dill, K. A. J. Am. Chem. Soc. 2002, 124, 12302.

(12) Birdi, K. S. Lipid and Biopolymer Monolayers at Liquid Interfaces Plenum Press: New York, 1989.

(13) Möhwald, H., in Phospholipid Monolayers, Handbook of Biological Physics, Vol. 1, Elsevier Science: Amsterdam, 1995.

(14) Dynarowicz-Latka, P.; Dhanabalan, A.; Oliveira, O. N. J. Adv. Colloid Int. Sci. 2001, 91, 221. 
(15) (a) Als-Nielsen, J.; Möhwald, H. In Handbook of Synchrotron Radiation, Vol. 4, Elsevier Science: Amsterdam, 1991. (b) Kaganer, V. M.; Möhwald, H.; Dutta, P. Rev. Mod. Phys. 1999, 71, 779.

(16) (a) Jacquemain, K.; Grayer Wolf, S.; Leveiller, F.; Deutsch, M.; Kjaer, K.; Als-Nielsen, J.; Lahav, M.; Leiserowitz, L. Ang. Chem. 1992, 104, 134. (b) Rapaport, H.; Kuzmenko, I.; Berfeld, M.; Kjaer, K.; Als-Nielsen, J.; Popovitz-Biro, R.; Weissbuch, I.; Lahav, M.; Leiserowitz, L. J. Phys. Chem. B 2000, 104, 1399. (c) Kuzmenko, I.; Rapaport, H.; Kjaer, K.; Als-Nielsen, J.; Weissbuch, I.; Lahav, M.; Leiserowitz, L. Chem. Rev. 2001, 101, 1659.

(17) Möhwald, H. Annu. Rev. Phys. Chem. 1990, 41, 441.

(18) Knobler, C. M. Adv. Chem. Phys. 1990, 77, 397.

(19) McConnell, H. M. Annu. Rev. Phys. Chem. 1991, 42, 171.

(20) (a) Hönig, D.; Möbius, D. J. Phys. Chem. 1991, 95, 4590. (b) Hönig, D.; Möbius, D. Thin Solid Films 1992, 210/211, 64.

(21) Henon, S.; Meunier, J. Rev. Sci. Instr. 1991, 62, 936.

(22) Weidemann, G.; Vollhardt, D. Colloids Surf. A 1995, 101, 187.

(23) Simon, S. A.; Lis, L. J.; Kauffman, J. W.; Macdonald, R. C. Biochim. Biophys. Acta 1975, 375,317 .

(24) Lis, L. J.; Parsegian, V. A.; Rand, R. P. Biochemistry 1981, 20, 1761.

(25) (a) Akutsu, H.; Seelig, J. Biochemistry 1981, 20, 7366. (b) Altenbach, C.; Seelig, J. ibid 1984, 23, 3913. (c) Macdonald, P. M.; Seelig, J. ibid 1987, 26, 1231. (d) Macdonald, P. M.; Seelig, J. ibid 1987, 26, 6292.

(26) Lösche, M.; Möhwald, H. J. Colloid Int. Sci. 1989, 131, 56.

(27) Roux, M.; Bloom, M. Biochemistry 1990, 29, 7077.

(28) Scarpa, M. V.; Maximiano, F. A.; Chaimovich, H.; Cuccovia, I. M. Langmuir 2002, 18, 8817. 
(29) Shah, D. O.; Schulman, J. H. J. Lipid Res. 1965, 6, 341.

(30) Kmetko, J.; Datta, A.; Evmenenko, G.; Dutta, P. J. Phys. Chem. B 2001, 105, 10818.

(31) Grigoriev, D.; Krustev, R.; Miller, R.; Pison, U. J. Phys. Chem. B 1999, 103, 1013.

(32) McLaughlin, S.; Bruder, A.; Chen, S.; Moser, C. Biochim. Biophys. Acta 1975, 394, 304.

(33) Hauser, H.; Hinckley, C. C.; Krebs, J.; Levine, B. A.; Phillips, M. C.; Williams, R. J. P. Biochim. Biophys. Acta 1977, 468, 364.

(34) Loosley-Millman, M. E.; Rand, R. P.; Parsegian, V. A. Biophys. J. 1982, 40, 221.

(35) (a) Tatulian, S. A. Biochim. Biophys. Acta 1983, 736, 189. (b) Tatulian, S. A.; Gordeliy, V. I.; Sokolova, A. E.; Syrykh, A. G. ibid 1991, 1070, 143.

(36) (a) Macdonald, P. M.; Seelig, J. Biochemistry 1988, 27, 6769. (b) Rydall, J. R.; Macdonald, P. M. ibid 1992, 31, 1092.

(37) Bartucci R.; Belsito, S.; Sportelli, L. Chem. Phys. Lipids 1996, 79, 171.

(38) Knock, M. M.; Bain, C. D. Langmuir 2000, 16, 2857.

(39) (a) Teppner, R.; Haage, K.; Wantke, D.; Motschmann, H. J. Phys. Chem. B 2000, 104, 11489. (b) Kölsch, P.; Motschmann, H. J. Phys. Chem. B, submitted.

(40) Meijer, L. A.; Leermakers, F. A. M.; Nelson, A. Langmuir 1994, 10, 1199.

(41) Gambu, I. ; Roux, B. J. Phys. Chem. B 1997, 101, 6066.

(42) Böckmann, R. A.; Hac, A.; Heimburg, T.; Grubmüller, H. Biophys. J. 2003, 85, 1647.

(43) Sachs, J. N. ; Woolf, T. B. J. Am. Chem. Soc. 2003, 125, 8742.

(44) Kjaer, K. Physica B 1989, 198, 100.

(45) Als-Nielsen, J. ; Jacquermain, J. ; Kjaer, K. ; Lahav, M.; Leveiller, F. ; Leiserowitz, L. Phys. Rep. 1994, 246, 251.

(46) Buffeteau, T. ; Desbat, B. ; Turlet, J. M. Appl. Spectrosc. 1991, 45, 380.

(47) Weidemann, G.; Vollhardt, D. Biophys. J. 1996, 70, 2758. 
(48) (a) McConlogue, C. W.; Vanderlick, T. K. Langmuir 1997, 13, 7158. (b) McConlogue, C. W.; Malamud, D.; Vanderlick, T. K. Biochim. Biophys. Acta 1998, 1372, 124. (c) McConlogue, C. W.; Vanderlick, T. K. Langmuir 1999, 15, 234.

(49) Kubo, I.; Adachi, S.; Maeda, H.; Seki, A. Thin Solid Films 2001, 393, 80.

(50) (a) Amador Kane S.; Compton, M.; Wilder, N. Langmuir 2000, 16, 8447. (b) Amador Kane S. ibid 2002, 18, 9853.

(51) (a) Keller, D. J.; McConnell, H. M.; Moy, V. T. J. Phys. Chem. 1986, 90, 2311. (b) Keller, D. J.; Korb, J. P.; McConnell, H. ibid 1987, 91, 6417.

(52) Vanderlick, T. K.; Möhwald, H. J. Chem. Phys. 1990, 94, 886.

(53) (a) Mitchell, M. L.; Dluhy, R. A. J. Am. Chem. Soc. 1988, 110, 712. (b) Dluhy, R. A.; Wright, N. A.; Griffiths, P. R. Appl. Spectros. 1988, 42, 138. (c) Hunt, R. D.; Mitchell, M. L.; Dluhy, R. A. J. Molec. Struct., 1989, 214, 93.

(54) Mendelsohn, R.; Flach, C. R. In Handbook of Vibrational Spectroscopy, Vol. 2, p. 1028, J. Wiley: New York, 2002; Mendelsohn, R.; Brauner, J.W; Gericke, A. Annu. Rev. Phys. Chem., 1995, 46, 305.

(55) Proudfoot, S. G.; Davdani, B. H. J. Pharm. Pharmacol. 1974, 26SUP, 121.

(56) Cleary, G. W.; Zatz, J. L. (a) J. Colloid Int. Sci. 1973, 45, 507; (b) J. Pharm. Sci. 1977, $66,975$.

(57) Sicre, P.; Cordoba, J. J. Colloid Int. Sci. 1989, 132, 94.

(58) Kabalnov, A.; Olsson, U.; Wennerström, H. J. Phys. Chem. 1995, 99, 6220. 
Table 1. Lattice parameters, $a, b$ and $\gamma$, tilt angle $t$ with respect to the normal, in-plane unit cell area $A_{x y}$, and chain cross-sectional area $A_{o}$ at different surface pressures.

\begin{tabular}{|c|c|c|c|c|c|c|c|}
\hline DPPC on & $\pi(\mathrm{mN} / \mathrm{m})$ & $a(\AA)$ & $b(\AA)$ & $\gamma\left({ }^{\circ}\right)$ & $\begin{array}{c}\mathrm{t} \\
(\mathrm{deg})\end{array}$ & $\begin{array}{l}\mathrm{A}_{\mathrm{xy}} \\
\left(\AA^{2}\right)\end{array}$ & $\begin{array}{c}\mathrm{A}_{\mathrm{o}} \\
\left(\AA^{2}\right)\end{array}$ \\
\hline \multirow[t]{4}{*}{$\mathrm{H}_{2} \mathrm{O}$} & 15 & 5.84 & 5.20 & 124.2 & 35.6 & 25.1 & 20.4 \\
\hline & 25 & 5.68 & 5.14 & 123.5 & 33.7 & 24.4 & 20.3 \\
\hline & 35 & 5.52 & 5.09 & 122.9 & 30.9 & 23.6 & 20.3 \\
\hline & 45 & 5.32 & 5.02 & 121.9 & 27.2 & 22.6 & 20.1 \\
\hline \multirow[t]{4}{*}{$\mathrm{NaBr} 0.5 \mathrm{M}$} & 15 & 5.84 & 5.20 & 124.2 & 35.8 & 25.1 & 20.4 \\
\hline & 25 & 5.66 & 5.14 & 123.4 & 33.2 & 24.3 & 20.3 \\
\hline & 35 & 5.49 & 5.08 & 122.7 & 31.2 & 23.5 & 20.1 \\
\hline & 45 & 5.30 & 5.02 & 121.9 & 26.4 & 22.6 & 20.2 \\
\hline \multirow[t]{4}{*}{$\mathrm{NaBr} 1.5 \mathrm{M}$} & 15 & 5.83 & 5.20 & 124.1 & 35.3 & 25.1 & 20.4 \\
\hline & 25 & 5.72 & 5.15 & 123.7 & 33.6 & 24.5 & 20.4 \\
\hline & 35 & 5.53 & 5.09 & 122.9 & 30.8 & 23.6 & 20.3 \\
\hline & 45 & 5.36 & 5.03 & 122.2 & 27.4 & 22.8 & 20.3 \\
\hline \multirow[t]{4}{*}{$\mathrm{NaI} 0.5 \mathrm{M}$} & 15 & no peaks & & & & & \\
\hline & 25 & too weak & & & & & \\
\hline & 35 & 5.45 & 5.08 & 122.4 & 28.4 & 23.4 & 20.5 \\
\hline & 45 & 5.29 & 5.02 & 121.8 & 24.8 & 22.6 & 20.5 \\
\hline $\mathrm{NaI} 1.5 \mathrm{M}$ & $\begin{array}{l}\text { all } \\
\text { pressures }\end{array}$ & $\begin{array}{c}\text { weak/bro } \\
\text { ad peak }\end{array}$ & & & & & \\
\hline
\end{tabular}


Table 2. DPPC monolayer stretching vibrations on pure water and on a $1.5 \mathrm{M} \mathrm{NaI}$ aqueous solution at $20^{\circ} \mathrm{C}$. The angle of incidence was $40^{\circ}$ normal to the surface of the monolayer.

\begin{tabular}{cccc}
\hline Vibration & $\boldsymbol{\pi}(\mathbf{m N} / \mathbf{m})$ & DPPC on water & DPPC on NaI 1.5 M \\
\hline$v_{a s} \mathrm{CH}_{2}$ & 15 & $2919.8 \pm 0.2$ & $2921.6 \pm 0.2$ \\
& 25 & $2919.5 \pm 0.2$ & $2920.0 \pm 0.2$ \\
& 35 & $2919.4 \pm 0.2$ & $2919.2 \pm 0.2$ \\
& 45 & $2919.1 \pm 0.2$ & $2919.1 \pm 0.2$ \\
${ }_{{ }_{s}} \mathrm{CH}_{2}$ & 15 & $2851.1 \pm 0.3$ & $2853.0 \pm 0.3$ \\
& 25 & $2851.0 \pm 0.3$ & $2851.6 \pm 0.3$ \\
& 35 & $2851.1 \pm 0.3$ & $2851.0 \pm 0.3$ \\
& 45 & $2851.1 \pm 0.3$ & $2851.0 \pm 0.3$ \\
$v_{a s} \mathrm{PO}_{2}^{-}$ & 15 & $1229.7 \pm 0.5$ & $1226.6 \pm 0.52$ \\
& 25 & $1231.5 \pm 0.5$ & $1228.0 \pm 0.5$ \\
& 35 & $1231.1 \pm 0.5$ & $1230.6 \pm 0.5$ \\
& 45 & $1230.2 \pm 0.5$ & $1231.1 \pm 0.5$ \\
\hline
\end{tabular}

